Article

\title{
Efficient Extraction of Vanadium from Vanadium-Titanium Magnetite Concentrate by Potassium Salt Roasting Additives
}

\author{
Renmin Li ${ }^{1,2, *}$, Tao Liu 1,2,3,*, Yimin Zhang ${ }^{1,2,3,4}$, Jing Huang ${ }^{1,2,3}$ and Chengbao Xu ${ }^{1,2}$ \\ 1 Hubei Collaborative Innovation Center for High Efficient Utilization of Vanadium Resources, \\ Wuhan 430081, China; zym126135@126.com (Y.Z.); crystal208@126.com (J.H.); xchb126@126.com (C.X.) \\ 2 College of Resource and Environmental Engineering, Wuhan University of Science and Technology, \\ Wuhan 430081, China \\ 3 Hubei Provincial Engineering Technology Research Center of High Efficient Cleaning Utilization for Shale \\ Vanadium Resource, Wuhan 430081, China \\ 4 College of Resource and Environment Engineering, Wuhan University of Technology, Wuhan 430070, China \\ * Correspondence: 15671600233@163.com (R.L.); liutao@wust.edu.cn (T.L.); Tel.: +86-027-6886-2057 (T.L.)
}

Received: 30 November 2017; Accepted: 10 January 2018; Published: 15 January 2018

\begin{abstract}
In this paper, potassium salt roasting additives were applied to extract vanadium from vanadium-titanium magnetite concentrate. Meanwhile, the mechanisms of potassium salt roasting and acid leaching kinetics were investigated. The results indicate that potassium salt roasting additives are more efficient than sodium and calcium salt and that $\mathrm{K}_{2} \mathrm{SO}_{4}$ works best. Under certain conditions (a dosage of $\mathrm{K}_{2} \mathrm{SO}_{4}$ of $4 \mathrm{wt} \%$, a roasting temperature of $900{ }^{\circ} \mathrm{C}$, a roasting time of $1 \mathrm{~h}$, a leaching temperature of $95^{\circ} \mathrm{C}$, a sulfuric acid concentration of $10 \%(v / v)$, and a leaching time of $1.5 \mathrm{~h}$ with a liquid to solid ratio of $3 \mathrm{~mL} / \mathrm{g}$ ) the vanadium leaching efficiency reached $71.37 \%$, an increase of $30.20 \%$ compared to that of blank roasting. Additionally, XRD and related SEM-EDS analyses indicated that $\mathrm{K}_{2} \mathrm{SO}_{4}$ fully destroyed the structure of vanadium-bearing minerals such as magnetite, and promoted the generation of soluble $\mathrm{KVO}_{3}$ to inhibit the formation of insoluble $\mathrm{Ca}\left(\mathrm{VO}_{3}\right)_{2}$ in the roasting process. Furthermore, it promoted the dissolution of sphene and the release of its vanadium in the leaching process, which increased the vanadium leaching efficiency significantly. Meanwhile, leaching kinetics analyses showed that the leaching process was controlled by internal diffusion; the apparent activation energy decreased from $37.43 \mathrm{~kJ} / \mathrm{mol}$ with blank roasting to $26.31 \mathrm{~kJ} / \mathrm{mol}$ with potassium salt roasting. The reaction order, with regards to the sulfuric acid concentration, decreased from 0.6588 to 0.5799 . Therefore, potassium salt roasting could improve mineral activity, accelerating the leaching process and reducing the dependence on high temperature and high acidity.
\end{abstract}

Keywords: vanadium extraction; vanadium-titanium magnetite; roasting additives; acid leaching; kinetics

\section{Introduction}

Vanadium is an important strategic resource for steel, aviation, chemical, battery and other industries, widely used for its superior properties [1]. In addition to vanadium-bearing shale, vanadium-titanium magnetite is another major raw material from which to extract vanadium. China's vanadium-titanium magnetite reserves are huge-up to 9.83 billion tons that reach mineable grade- and are therefore of high utilization value [2,3].

Generally, the indirect vanadium extraction process takes place after iron-making; vanadium elements are enriched into the slag to obtain vanadium slag and then vanadium is extracted from the slag. The indirect vanadium extraction process is widely used in the industry $[2,4,5]$ in combination with the blast furnace process and could greatly improve the production efficiency [6-8]. In recent 
years, a large amount of vanadium-titanium magnetite deposit was discovered in Chao-yang, China. Compared with the vanadium-titanium magnetite concentrate from Pan-xi and Cheng-de, China, it was unique for its characteristics of high grades of vanadium and titanium and a low grade of iron [9]. The poor quality of the iron resulted in it being unsuitable for priority of the iron-making and indirect vanadium extraction processes; thus, it was more suitable for the direct vanadium extraction process. In general, the direct vanadium extraction process is applied by sodium salt roasting and water leaching $[10,11]$ or calcium salt roasting and acid leaching [12]. The vanadium was dissolved in the leachate, then the operations of purification, enrichment, precipitation and calcination were applied to obtain the product of $\mathrm{V}_{2} \mathrm{O}_{5}[1,13]$. Furthermore, prioritized extraction of vanadium, combined with the separation of titanium-iron and the utilization of titanium slag, was expected to achieve comprehensive utilization of vanadium, titanium, and iron [9].

In most cases, vanadium elements of vanadium-titanium magnetite mainly exist in magnetite phase in the form of isomorphous substitution of iron $[9,14,15]$. Therefore, the key to releasing vanadium is breaking the magnetite lattice structure; however, the stable structure of magnetite can be only fully destroyed at a high temperature with an oxidizing atmosphere [16,17]. Thus, the roasting process is crucial for the release and extraction of vanadium; the roasting process has proved to be particularly effective in the hydrometallurgical field [18,19]. The quality of the roasting process determines the recovery of vanadium; in general, roasting additives are added to strengthen the effect of the roasting process [20]. Roasting additives and related process conditions are essential but there are many problems with traditional sodium salt and calcium additives. With sodium salt additives, in order to obtain a higher vanadium leaching efficiency, a large amount of sodium salt needs to be added, resulting in polluting gases being generated and difficult treatment $[2,15,16]$; With calcium salt additives, problems such as large consumption of additives, high selectivity for roasting material, and the high cost of vanadium extraction are obvious [12,21]. Considering that potassium and sodium both belong to the alkali metal elements, they are similar in chemical properties but potassium is livelier and easier to use in chemical reactions [22]. According to the reaction of vanadium extraction in the sodium salt roasting process [23], it can be speculated that potassium salt could promote the degree of positive reaction, which is more conducive to the extraction of vanadium.

In this paper, we attempted to apply potassium salt as a roasting additive to strengthen the vanadium extraction from the vanadium-titanium magnetite concentrate. At the same time, phase transformation analyses were conducted to reveal the mechanism by which potassium salt strengthens the vanadium extraction and the kinetics model was established to further explain the effect of potassium salt.

\section{Experimental}

\subsection{Materials}

The vanadium-titanium magnetite ore used in the experiment was from Chao-yang, China. After crushing and grinding, the particle size of the ore was $-0.074 \mathrm{~mm}$, accounting for $65 \%$ of the total particle size. In accordance with our previous work [9] obtaining the concentrate, the ore was concentrated by weak magnetic separation. All reagents $\left(\mathrm{K}_{2} \mathrm{SO}_{4}, \mathrm{~K}_{2} \mathrm{CO}_{3}, \mathrm{Na}_{2} \mathrm{SO}_{4}, \mathrm{Na}_{2} \mathrm{CO}_{3}, \mathrm{CaSO}_{4}\right.$, $\mathrm{CaCO}_{3}$ and sulfuric acid) used in the test were of analytical grade.

The results of the main chemical composition of the concentration are illustrated in Table 1; chemical phase analyses of vanadium in the concentration which was measured by sequential extraction procedures [24] are illustrated in Table 2, and the XRD (X-ray diffraction) pattern of the concentrate is illustrated in Figure 1. Table 1 shows that the iron grade of the concentrate is low; as a result, it is not suitable for direct iron-making and indirect extraction of vanadium; the grade of vanadium and titanium is relatively high, and the grade of vanadium is above $1 \%$, suitable for direct extraction of vanadium. Table 2 shows that the main vanadium-bearing minerals are magnetite- $\mathrm{FeO}(\mathrm{Fe}, \mathrm{V})_{2} \mathrm{O}_{3}$ and sphene- $\mathrm{Ca}(\mathrm{Ti}, \mathrm{V}) \mathrm{SiO}_{4} \mathrm{O}$ [9]. The key to extracting vanadium is to 
destroy the structure of the vanadium-bearing mineral. Therefore, according to the occurrence of vanadium, damaging the magnetite structure requires a high temperature $[16,17]$ and the sphene (silicate minerals) can be dissolved by acid. Furthermore, in our previous work, the vanadium leaching efficiency of direct leaching was below $15 \%$ and water leaching was below $20 \%$ which proved that the roasting process and acid leaching were both necessary for the extraction of vanadium. Thus, roasting-acid leaching was selected as a reasonable process for the extraction of vanadium from the concentration. Meanwhile, Figure 1 shows that the main minerals in the concentrate include magnetite, ilmenite and sphene.

Table 1. Analyses of the main chemical composition of the concentrate wt $\%$.

\begin{tabular}{cccccccccc}
\hline Element & $\mathrm{V}_{\mathbf{2}} \mathrm{O}_{\mathbf{5}}$ & $\mathrm{TiO}_{2}$ & $\mathrm{TFe}$ & $\mathrm{SiO}_{2}$ & $\mathrm{Al}_{2} \mathrm{O}_{3}$ & $\mathrm{CaO}$ & $\mathbf{M g O}$ & $\mathrm{S}$ & $\mathbf{C u}$ \\
\hline Content & 1.10 & 19.72 & 44.2 & 9.85 & 3.14 & 4.71 & 0.78 & 0.026 & 0.002 \\
\hline
\end{tabular}

Table 2. Chemical phase analyses of vanadium in the concentrate wt $\%$.

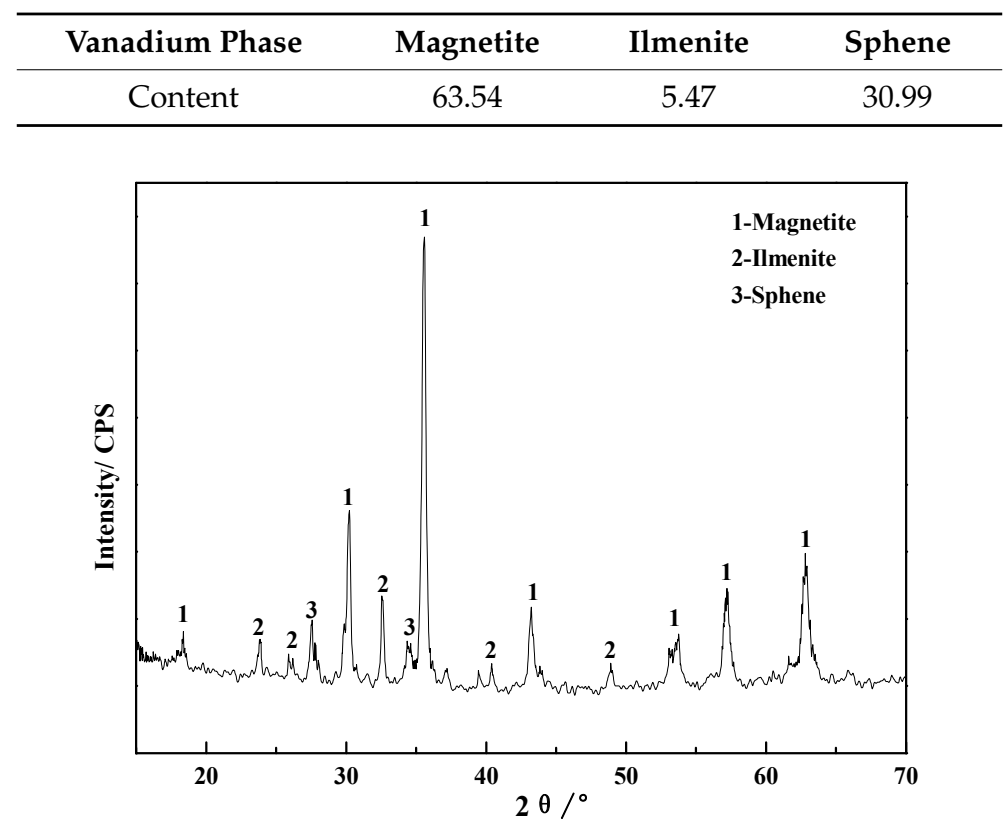

Figure 1. XRD pattern of the concentrate.

\subsection{Procedure and Methods}

The concentrate was added into the corundum crucible; then, a certain amount of additives were put into it and mixed completely; it was roasted at the required temperature for a period of time in a muffle furnace, then cooled to room temperature to obtain roasting slag. The roasting slag was placed in a beaker, sulfuric acid was added and leached on a magnetic stirrer at a constant temperature for a period of time, then filtered to obtain leachate.

The content of vanadium in the leachate was determined by the ferrous volumetric method and the vanadium leaching efficiency was calculated according to the following equation [25]:

$$
\beta=\frac{C_{\mathrm{Vl}} \cdot \mathrm{V}}{C_{\mathrm{Vs}} \cdot \mathrm{M}}
$$

where $\beta$ is the vanadium leaching efficiency $(\%), C_{V l}$ is the vanadium content in the leachate $(\mathrm{g} / \mathrm{mL})$, $\mathrm{C}_{\mathrm{Vs}}$ is the grade of vanadium in the concentrate (\%), $\mathrm{V}$ is the volume of the leachate $(\mathrm{mL})$, and $\mathrm{M}$ is the mass of the concentrate $(\mathrm{g})$. 
It is true that mass loss can occur after the roasting process. However, the mass loss was below $1 \%$ in our experiment, which can be seen as normal experimental error and ignored. Thus, the vanadium content in the concentrate can be regarded as constant before and after roasting and so calculating the vanadium leaching efficiency based on vanadium content in the concentrate is rational.

The main chemical composition of the concentrate was determined by (ICP-AES) inductivelycoupled plasma-atomic emission spectroscopy (Thermo Elemental, Boston, MA, USA).

Phase compositions were obtained by an X-ray diffractometer (D/MAX2500PC, Rigaku, Tokyo, Japan) with $\mathrm{Cu}-\mathrm{K} \alpha$ radiation.

Microscopic observation and elemental analyses (SEM with EDS) were conducted by using a JEOL IT 300 scanning electronic microscope (JEOL, Tokyo, Japan) equipped with an energy dispersive spectrometer (EDS, X-Act, Oxford, London, Britain, UK).

\section{Results and Discussion}

\subsection{Roasting Process}

\subsubsection{Effect of Different Additives and Their Dosage on the Vanadium Leaching Efficiency}

The effect of different additives and their dosage on the vanadium leaching efficiency was investigated under the following conditions: a roasting temperature of $900{ }^{\circ} \mathrm{C}$, a roasting time of $1 \mathrm{~h}$, a leaching temperature of $95^{\circ} \mathrm{C}$, a sulfuric acid concentration of $15 \%(v / v)$, and a leaching time of $1.5 \mathrm{~h}$ with a liquid to solid ratio of $3 \mathrm{~mL} / \mathrm{g}$. The results are illustrated in Figure 2. As shown in Figure 2, the effects of potassium salt additives are significantly better than sodium and calcium salt additives, and the effects of calcium salt additives are not quite significant.

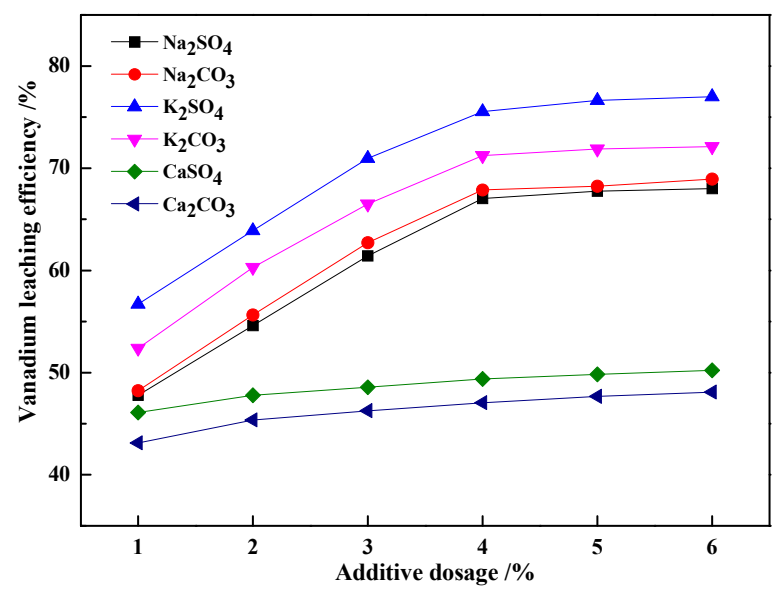

Figure 2. Effect of different additives and their dosage on the vanadium leaching efficiency.

Related research has shown that vanadate formed during the roasting process; therefore, the formation of insoluble $\mathrm{Ca}\left(\mathrm{VO}_{3}\right)_{2}$ may be the reason for the lower vanadium leaching efficiency in calcium salt roasting [25]. The reactions of sodium salt roasting and potassium salt roasting [22] are illustrated in Equations (2) and (3). $\mathrm{Na}_{2} \mathrm{O}$ and $\mathrm{K}_{2} \mathrm{O}$ both belong to ionic compounds and have similar properties; the radius of $\mathrm{K}^{+}$is bigger than $\mathrm{Na}^{+}$; as a result, the lattice energy of $\mathrm{K}_{2} \mathrm{O}$ is lower than $\mathrm{Na}_{2} \mathrm{O}$ [26], which indicates that $\mathrm{K}_{2} \mathrm{O}$ is more reactive, inferring that the extent of the reaction of Equation (3) is greater than that of Equation (2). Thus, the vanadium leaching efficiency of potassium salt roasting is higher than that of sodium salt roasting. In particular, $\mathrm{K}_{2} \mathrm{SO}_{4}$ is the most significant for its decomposition product $\left(\mathrm{SO}_{2}\right)$ which could react with $\mathrm{CaO}$ (in the concentrate) to generate $\mathrm{CaSO}_{4}$ to inhibit the formation of $\mathrm{Ca}\left(\mathrm{VO}_{3}\right)_{2}$ [22]; related reactions are illustrated in Equations (4) and (5). Thus, $\mathrm{K}_{2} \mathrm{SO}_{4}$ is selected as the roasting additive. 
The increase of the vanadium leaching efficiency is not significant when the $\mathrm{K}_{2} \mathrm{SO}_{4}$ dosage exceeds $4 \mathrm{wt} \%$. Therefore, the optimal dosage of $\mathrm{K}_{2} \mathrm{SO}_{4}$ is $4 \mathrm{wt} \%$.

$$
\begin{gathered}
\mathrm{Na}_{2} \mathrm{O}+\mathrm{V}_{2} \mathrm{O}_{5} \rightarrow \mathrm{NaVO}_{3} \\
\mathrm{~K}_{2} \mathrm{O}+\mathrm{V}_{2} \mathrm{O}_{5} \rightarrow \mathrm{KVO}_{3} \\
\mathrm{~K}_{2} \mathrm{SO}_{4} \rightarrow \mathrm{K}_{2} \mathrm{O}+\mathrm{SO}_{2}+\mathrm{O}_{2} \\
\mathrm{CaO}+\mathrm{SO}_{2}+\mathrm{O}_{2} \rightarrow \mathrm{CaSO}_{4}
\end{gathered}
$$

\subsubsection{Effect of Roasting Temperature and Roasting Time on Vanadium Leaching Efficiency}

In the roasting process, the roasting slag was leached under the following conditions: a leaching temperature of $95^{\circ} \mathrm{C}$, a leaching time of $1.5 \mathrm{~h}$, and a sulfuric acid concentration of $10 \%(v / v)$ with a liquid to solid ratio of $3 \mathrm{~mL} / \mathrm{g}$.

The effect of roasting temperature on the vanadium leaching efficiency was researched under these conditions: $\mathrm{K}_{2} \mathrm{SO}_{4}$ dosage was 0 or $4 \mathrm{wt} \%$ and the roasting time was $1 \mathrm{~h}$; the results are illustrated in Figure 3a. It can be observed that the vanadium leaching efficiency first increases and then decreases as the material melts [25] with the increase in temperature, reaching the maximum value at $900{ }^{\circ} \mathrm{C}$. Therefore, the optimal roasting temperature is $900{ }^{\circ} \mathrm{C}$.

The effect of roasting time on the vanadium leaching efficiency was investigated under these conditions: $\mathrm{K}_{2} \mathrm{SO}_{4}$ dosage was 0 or $4 \mathrm{wt} \%$ and the roasting temperature was $900{ }^{\circ} \mathrm{C}$; the results are illustrated in Figure $3 b$. It can be observed that the vanadium leaching efficiency continues to rise and reaches the maximum value at $1 \mathrm{~h}$, and the vanadium leaching efficiency begins to decrease because of sintering [27] when the roasting time is above $1 \mathrm{~h}$. Thus, the optimal roasting time is $1 \mathrm{~h}$.

In particular, at the same roasting temperature or roasting time, potassium salt roasting (the dosage of $\mathrm{K}_{2} \mathrm{SO}_{4}$ was $4 \mathrm{wt} \%$ in the roasting process) could improve the vanadium leaching rate greatly compared to blank roasting (the dosage of $\mathrm{K}_{2} \mathrm{SO}_{4}$ was $0 \mathrm{wt} \%$ in the roasting process).

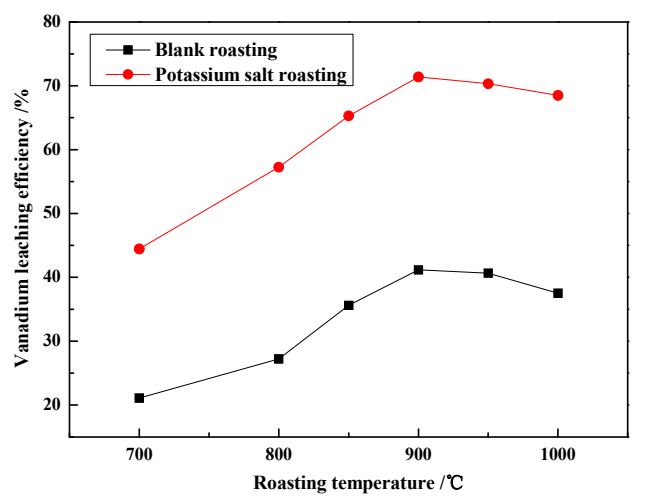

(a)

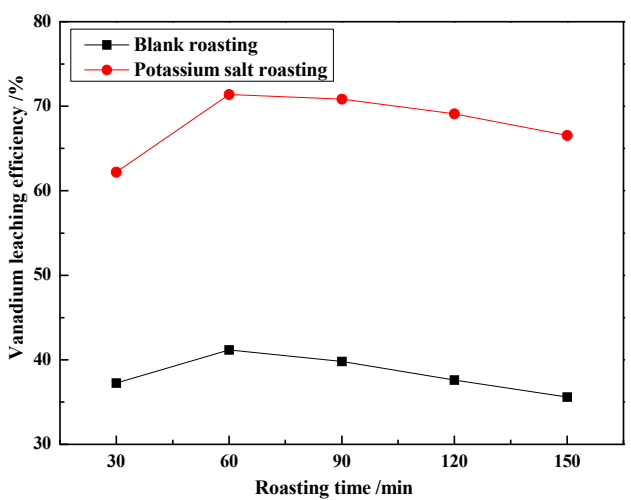

(b)

Figure 3. (a) Effect of roasting temperature on the vanadium leaching efficiency; (b) Effect of roasting time on the vanadium leaching efficiency.

\subsubsection{Analyses of Phase Transformation in the Roasting Process}

The phase transformation between the concentrate, blank roasting slag and potassium salt roasting slag was analyzed by XRD, and the XRD patterns are illustrated in Figure 4 (this roasting slag was obtained at roasting conditions of $900{ }^{\circ} \mathrm{C}$ for $1 \mathrm{~h}$ ).

Comparing the XRD patterns of Figure $4 \mathrm{~b}$ with Figure $4 \mathrm{a}$, the diffraction peaks of the magnetite phase $\left(\mathrm{Fe}_{3} \mathrm{O}_{4}\right.$-main vanadium-bearing mineral) are weakened when the diffraction peaks of the hematite phase $\left(\mathrm{Fe}_{2} \mathrm{O}_{3}\right)$ appear, inferring that blank roasting could damage the structure of 
magnetite [7] to some extent. Specifically, the diffraction peaks of the ilmenite phase $\left(\mathrm{FeTiO}_{3}\right)$ disappear at the same time as the diffraction peaks of the pseudobrookite phase $\left(\mathrm{Fe}_{2} \mathrm{TiO}_{5}\right)$ appear, indicating that the structure of ilmenite is fully damaged.

Comparing the XRD patterns of Figure $4 c$ with Figure $4 b$, the diffraction peaks of the magnetite phase $\left(\mathrm{Fe}_{3} \mathrm{O}_{4}\right)$ disappear completely while the diffraction peaks of the hematite phase $\left(\mathrm{Fe}_{2} \mathrm{O}_{3}\right)$ are greatly strengthened. Thus, it can be observed that roasting additive $\mathrm{K}_{2} \mathrm{SO}_{4}$ could fully destroy the structure of magnetite for its decomposition product $\mathrm{O}_{2}$ [22] which could further react with magnetite, which is beneficial to the release and extraction of vanadium; the related reaction is illustrated in Equation (6).

$$
\mathrm{FeO}(\mathrm{Fe}, \mathrm{V})_{2} \mathrm{O}_{3}+\mathrm{O}_{2} \rightarrow \mathrm{Fe}_{2} \mathrm{O}_{3}+\mathrm{V}_{2} \mathrm{O}_{5}
$$

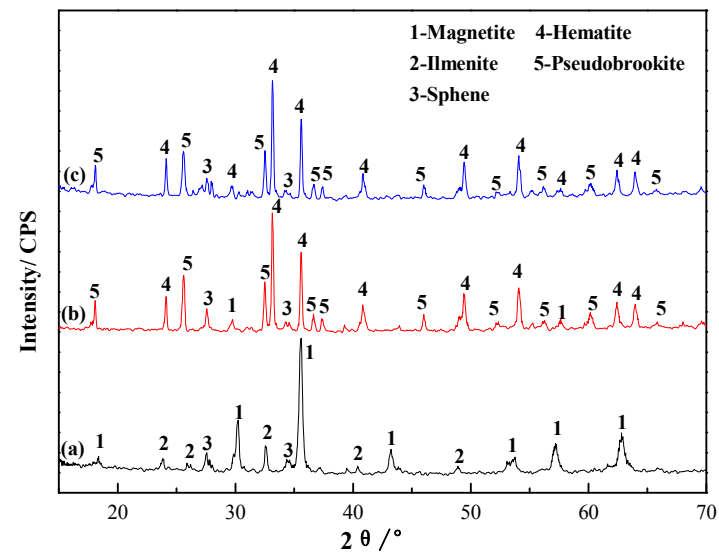

Figure 4. XRD patterns of different samples (a) concentrate; (b) blank roasting slag; (c) potassium salt roasting slag.

In order to further study the role of $\mathrm{K}_{2} \mathrm{SO}_{4}$ in extracting vanadium from the vanadium-titanium magnetite concentrate, an SEM micrograph and related EDS analyses of the blank roasting slag and the potassium salt roasting slag are illustrated in Figure 5.

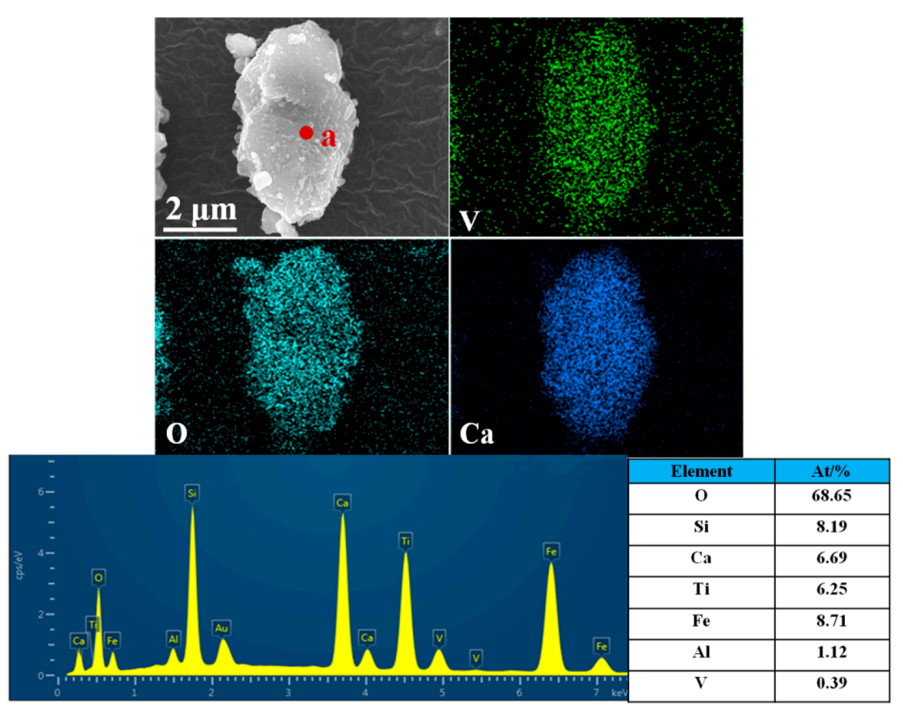

(a)

Figure 5. Cont. 


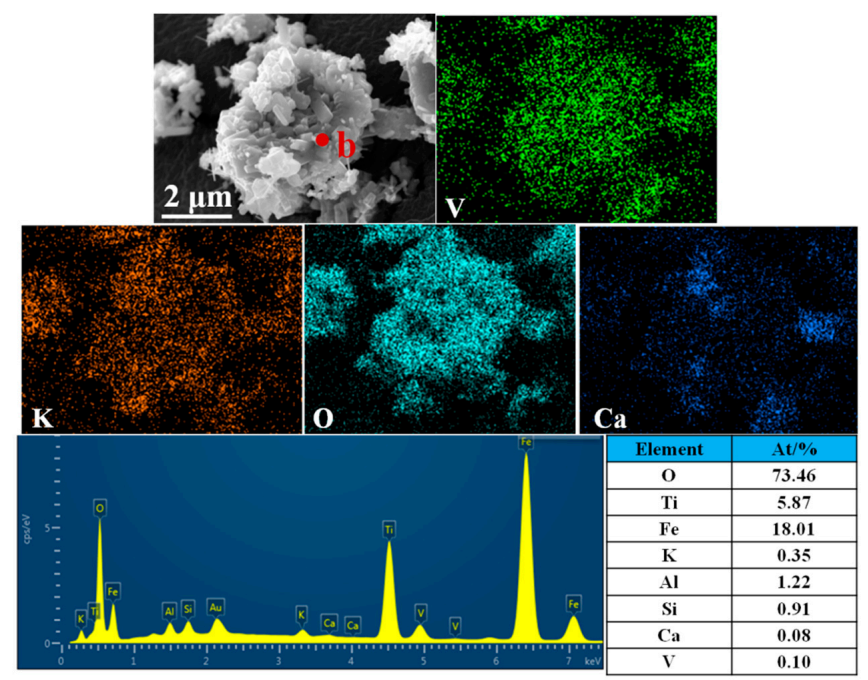

(b)

Figure 5. SEM micrograph and related EDS analyses. (a) blank roasting slag; (b) potassium salt roasting slag.

As presented in Figure 5a,b, the blank roasting slag has a smooth surface with a dense structure; the potassium salt roasting slag has a comparatively rough surface with a loose structure. Therefore, combined with the results of XRD analyses, it can be observed that when the vanadium-titanium magnetite was roasted with $\mathrm{K}_{2} \mathrm{SO}_{4}$, the structure of vanadium-bearing minerals was destroyed more thoroughly, and the mineral particles became looser, which is more conducive to the leaching of vanadium.

The great relevance of $\mathrm{V}, \mathrm{O}, \mathrm{Ca}$ shown in Figure 5a means that the vanadium element of the blank roasting slag may be in the form of $\mathrm{Ca}\left(\mathrm{VO}_{3}\right)_{2}$, which is difficult to leach with sulfuric acid. However, Figure $5 \mathrm{~b}$ shows that the relevance of $\mathrm{V}, \mathrm{O}, \mathrm{K}$ is obvious and the relevance of $\mathrm{V}, \mathrm{O}, \mathrm{Ca}$ is not significant; it can be speculated that the $\mathrm{KVO}_{3}$ existed in the potassium salt roasting slag and the generation of $\mathrm{Ca}\left(\mathrm{VO}_{3}\right)_{2}$ was inhibited. Furthermore, the solubility of $\mathrm{KVO}_{3}$ in sulfuric acid solution is greater than $\mathrm{Ca}\left(\mathrm{VO}_{3}\right)_{2}[22,25]$, which indicates that the generation of $\mathrm{KVO}_{3}$ may be the main cause of the significant increase in the vanadium leaching efficiency of the potassium salt roasting slag compared to that of the blank roasting slag.

Based on the above analyses and Equations (2)-(6), the reaction of the vanadium-titanium magnetite concentrate roasted with $\mathrm{K}_{2} \mathrm{SO}_{4}$ can be illustrated with Equation (7).

$$
\mathrm{FeO}(\mathrm{Fe}, \mathrm{V})_{2} \mathrm{O}_{3}+\mathrm{K}_{2} \mathrm{SO}_{4}+\mathrm{CaO}+\mathrm{O}_{2} \rightarrow \mathrm{Fe}_{2} \mathrm{O}_{3}+\mathrm{KVO}_{3}+\mathrm{CaSO}_{4}
$$

\subsection{Leaching Process}

3.2.1. Effect of Leaching Temperature and Sulfuric Acid Concentration on the Vanadium Leaching Efficiency

In the leaching process, the roasting slag was obtained under these conditions: a roasting temperature of $900{ }^{\circ} \mathrm{C}$ and a roasting time of $1 \mathrm{~h}$.

The vanadium leaching efficiency in the roasting slag with the sulfuric acid concentration of $10 \%(v / v)$ and a liquid to solid ratio of $3 \mathrm{~mL} / \mathrm{g}$ were studied under different leaching temperatures. The results are illustrated in Figure 6a. It can be observed that with the leaching temperature and leaching time increasing, the vanadium leaching efficiency underwent sustained rapid growth. Therefore, a leaching temperature of $95^{\circ} \mathrm{C}$ was selected. 
The vanadium leaching efficiency in the roasting slag with the leaching temperature of $95{ }^{\circ} \mathrm{C}$ and a liquid to solid ratio of $3 \mathrm{~mL} / \mathrm{g}$ was studied under different sulfuric acid concentrations. The results are illustrated in Figure $6 \mathrm{~b}$. It can be observed that, with the increase in sulfuric acid concentration, the vanadium leaching efficiency continues to increase sharply. However, when the sulfuric acid concentration exceeded $10 \%(v / v)$, the growth of the vanadium leaching efficiency was moderate. With the comprehensive consideration of iron loss, acid consumption, and the purification of leachate [28,29], we determined that the appropriate sulfuric acid concentration is $10 \%(v / v)$. Nevertheless, when the leaching time exceeds $1.5 \mathrm{~h}$, the vanadium leaching efficiency does not significantly increase. Thus, the suitable leaching time should be $1.5 \mathrm{~h}$. With this leaching time, the vanadium leaching efficiency is $71.37 \%$.

Additionally, under the same conditions of leaching temperature and sulfuric acid concentration, the vanadium leaching efficiency of potassium salt roasting was higher.
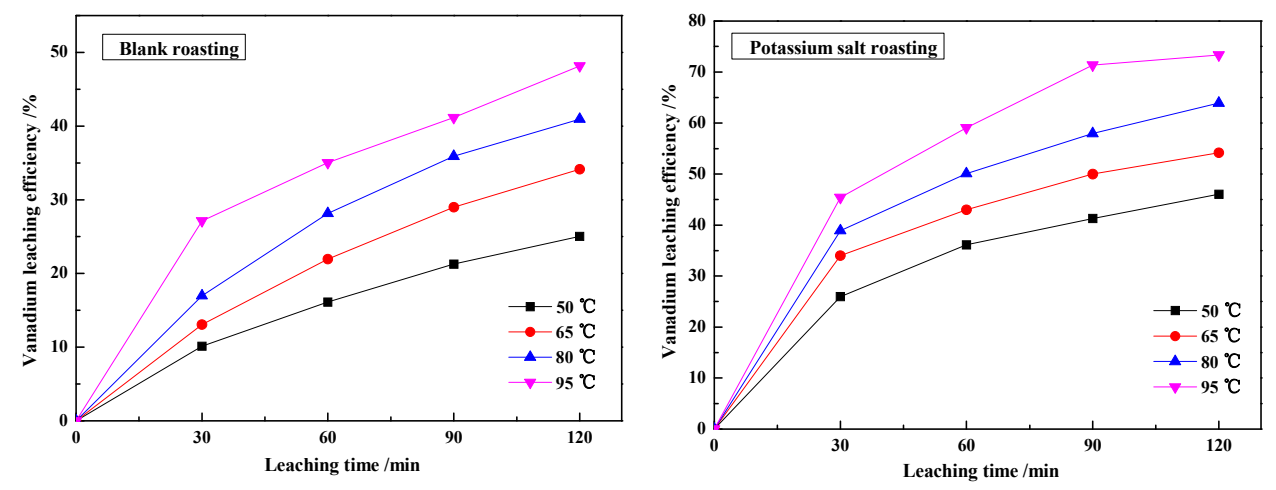

(a)
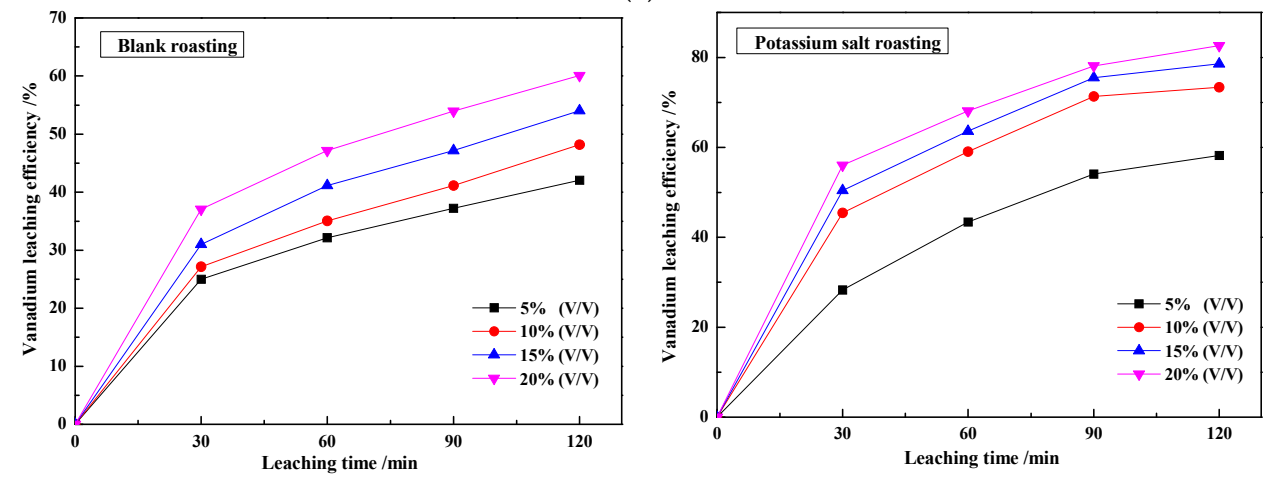

(b)

Figure 6. (a) Effect of leaching temperature on the vanadium leaching efficiency; (b) Effect of sulfuric acid concentration on the vanadium leaching efficiency.

\subsubsection{Analyses of Phase Transformation in the Leaching Process}

The phase transformation between the leaching slag of blank roasting and the leaching slag of potassium roasting was analyzed by XRD, and the XRD patterns are illustrated in Figure 7 (this leaching slag was obtained at these conditions: a sulfuric acid concentration of $10 \%$ and leaching at $95{ }^{\circ} \mathrm{C}$ for $1.5 \mathrm{~h}$ with a liquid to solid ratio of $3 \mathrm{~mL} / \mathrm{g}$ ).

Comparing the XRD patterns of Figure 7a with those of Figure $7 \mathrm{~b}$, the diffraction peaks of the sphene phase ( $\mathrm{CaTiSiO}_{4} \mathrm{O}$-main vanadium-bearing mineral) disappear; at the same time, the diffraction peaks of the gypsum phase $\left(\mathrm{CaSO}_{4} \cdot 2 \mathrm{H}_{2} \mathrm{O}\right)$ appear, indicating that sphene has been fully dissolved by sulfuric acid to generate gypsum when roasting with $\mathrm{K}_{2} \mathrm{SO}_{4}$, which is conducive to the leaching of vanadium. Furthermore, it can be inferred that $\mathrm{KVO}_{3}-$ which is more soluble- -has been dissolved, improving the vanadium leaching efficiency greatly. Moreover, the fact that sphene in the leaching slag 
of blank roasting could not be fully dissolved by sulfuric acid may be due to the formation of insoluble $\mathrm{Ca}\left(\mathrm{VO}_{3}\right)_{2}$ in the roasting process which consumes a portion of acid, providing further evidence to prove that potassium roasting could inhibit the formation of $\mathrm{Ca}\left(\mathrm{VO}_{3}\right)_{2}$ when generating $\mathrm{KVO}_{3}$.

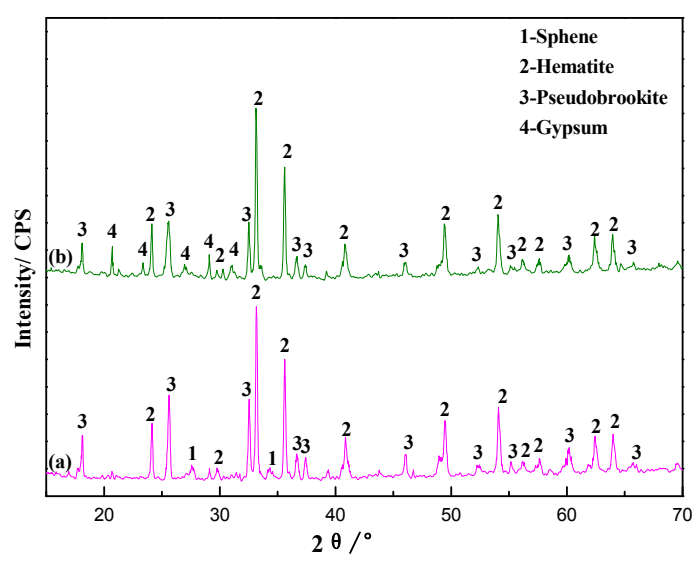

Figure 7. XRD patterns of different samples. (a) leaching slag of blank roasting; (b) leaching slag of potassium roasting.

Summing up the above analysis, the mechanism by which $\mathrm{K}_{2} \mathrm{SO}_{4}$ extracts vanadium from the vanadium-titanium magnetite concentrate is illustrated in Figure 8.

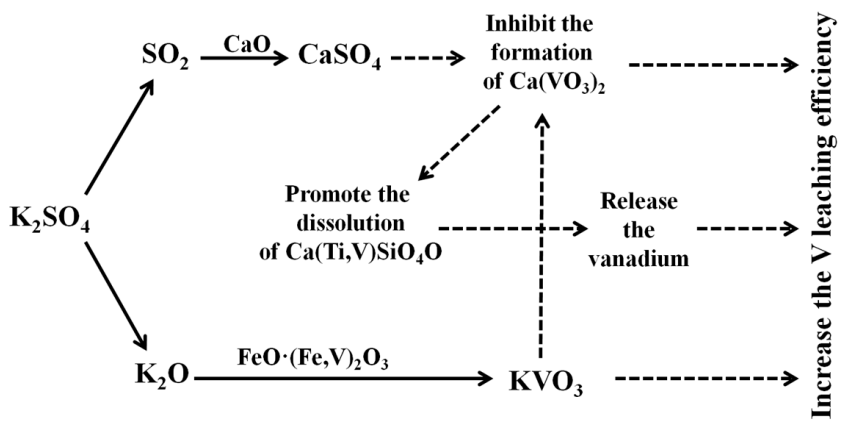

Figure 8. Mechanism by which $\mathrm{K}_{2} \mathrm{SO}_{4}$ extracts vanadium from the concentrate.

For a fuller interpretation of the data, the mass balance of vanadium in the roasting and leaching process is illustrated in Figure 9.

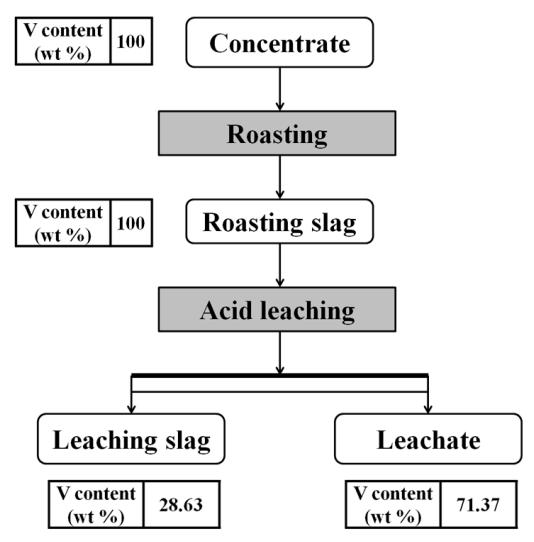

Figure 9. The mass balance of vanadium in the roasting and leaching process. 


\subsection{Kinetics Analyses of Vanadic Acid Leaching Process}

The acid leaching process of vanadium-titanium magnetite potassium roasting slag is a solid-liquid reaction. Considering the fact that the particles are spherical, the irreversibility of the reaction, and the formation of the solid residual layer, it follows the typical nuclear contraction model, i.e., the shrinking core model (SCM) [27,30,31]. Drawn from this model, under vigorous stirring conditions, a control step of diffusion film can be ignored, focusing on the influence of the chemical reaction and diffusion rate on the leaching rate [27].

When the reaction is controlled by internal diffusion, it follows this equation [27]:

$$
1-2 \mathrm{r} / 3-(1-\mathrm{r})^{2 / 3}=\mathrm{kt}
$$

Analogously, when the reaction is controlled by a chemical reaction, it follows this equation [27]:

$$
1-(1-\mathrm{r})^{1 / 3}=\mathrm{kt}
$$

where $\mathrm{r}$ is the vanadium leaching efficiency (\%); $\mathrm{k}$ is the apparent reaction rate constant; $\mathrm{t}$ is the leaching time (min).

The particle size of roasting slag used in kinetics analyses was $\mathrm{P}_{80}=0.104 \mathrm{~mm}$. Notably, the roasting slag used in the kinetics analyses was obtained under the same conditions of roasting at $900{ }^{\circ} \mathrm{C}$ for $1 \mathrm{~h}$, and the test materials were the same batch; thus, the particle size was fixed in kinetics analyses.

\subsubsection{Calculation of Apparent Activation Energy}

Substituting the experimental data in Figure 6a to Equations (8) and (9), the fitting results are illustrated in Figures 10 and 11. This indicates that the leaching process of potassium salt roasting and blank roasting are both anastomosis with Equation (8) rather than Equation (9). Therefore, the leaching process is mainly controlled by internal diffusion.

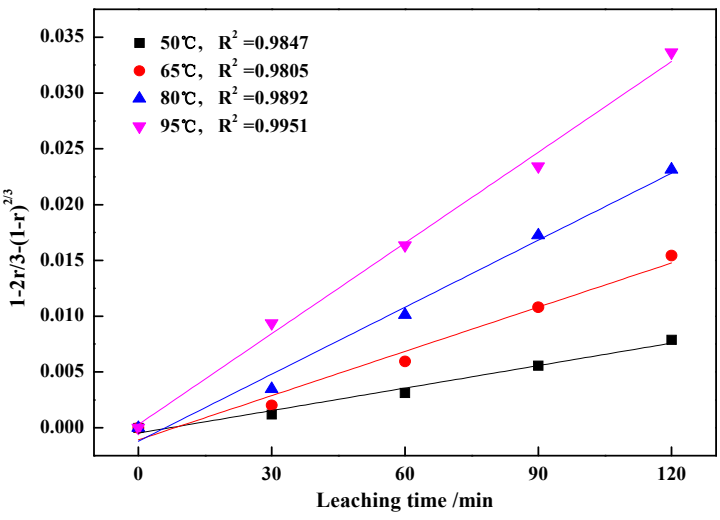

(a)

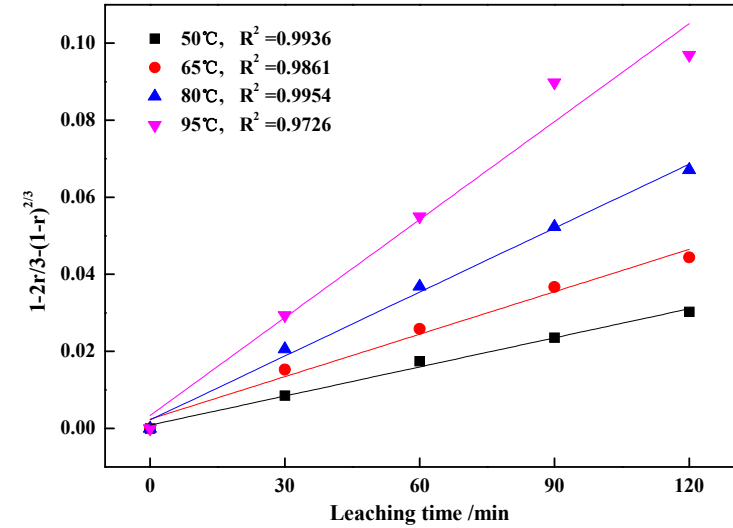

(b)

Figure 10. Fitting plots of Equation (8) versus time at different temperatures. (a) blank roasting; (b) potassium salt roasting.

According to the Arrhenius integral equation:

$$
\ln \mathrm{k}=-\mathrm{E} / \mathrm{RT}+\ln \mathrm{A}
$$

where $\mathrm{k}$ is the apparent reaction rate constant, $\mathrm{E}$ is the apparent activation energy $(\mathrm{kJ} / \mathrm{mol}), \mathrm{R}$ is the gas constant $(8.314 \mathrm{~J} / \mathrm{K} \cdot \mathrm{mol}), \mathrm{T}$ is the thermodynamic temperature $(\mathrm{K})$, and $\mathrm{A}$ is the frequency factor. 
It can be drawn from Equation (10) that lnk and 1/T have a linear relationship, and the slope is $-E / R$. Therefore, the apparent activation energy can be calculated by the slope $-E / R$. The logarithm of the reaction rate constant $k$ of roasting slag in acid leaching and the reciprocal of the temperature $\mathrm{T}$ are plotted, and the results are illustrated in Figure 12.

From the slope presented in Figure 12, the apparent activation energy of blank roasting can be calculated as $37.43 \mathrm{~kJ} / \mathrm{mol}$; analogously, for potassium salt roasting, this is $26.31 \mathrm{~kJ} / \mathrm{mol}$. Classic kinetics theory [32,33] considered the apparent activation energy to be $>40 \mathrm{~kJ} / \mathrm{mol}$ while the leaching reaction is controlled by the chemical reaction; in contrast, this was $<40 \mathrm{~kJ} / \mathrm{mol}$ when controlled by internal diffusion. In this paper, the apparent activation energy was $<40 \mathrm{~kJ} / \mathrm{mol}$, providing further evidence to prove that the acid leaching process was controlled by internal diffusion. Meanwhile, the apparent activation energy could be obviously reduced when the vanadium-titanium magnetite was roasted with potassium salt. Moreover, the activity of the reactants was improved and the dependency of the reaction on a high temperature was weakened.

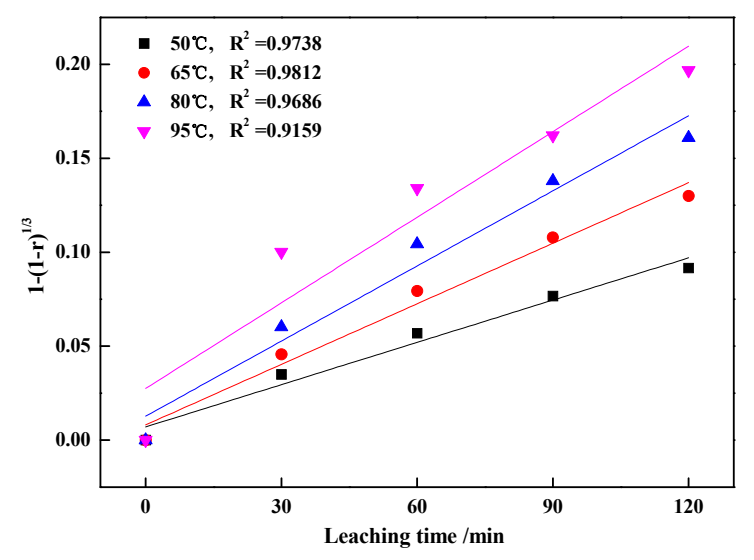

(a)

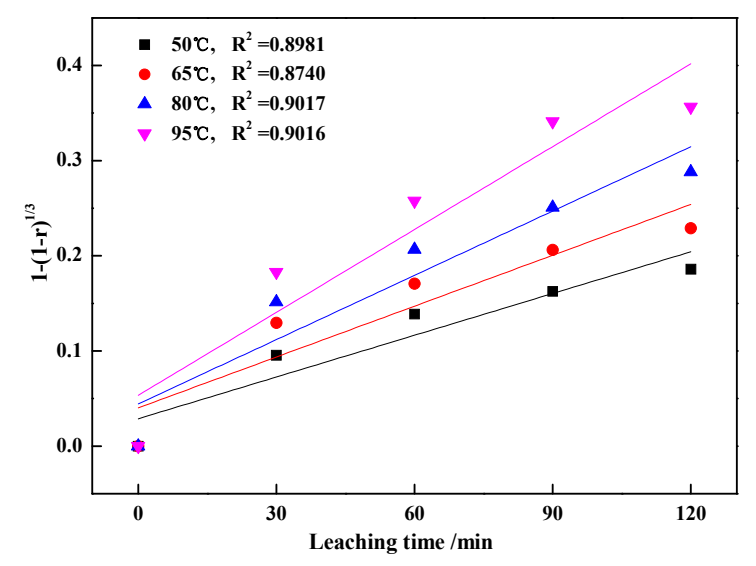

(b)

Figure 11. Fitting plots of Equation (9) versus time at different temperatures. (a) blank roasting; (b) potassium salt roasting.

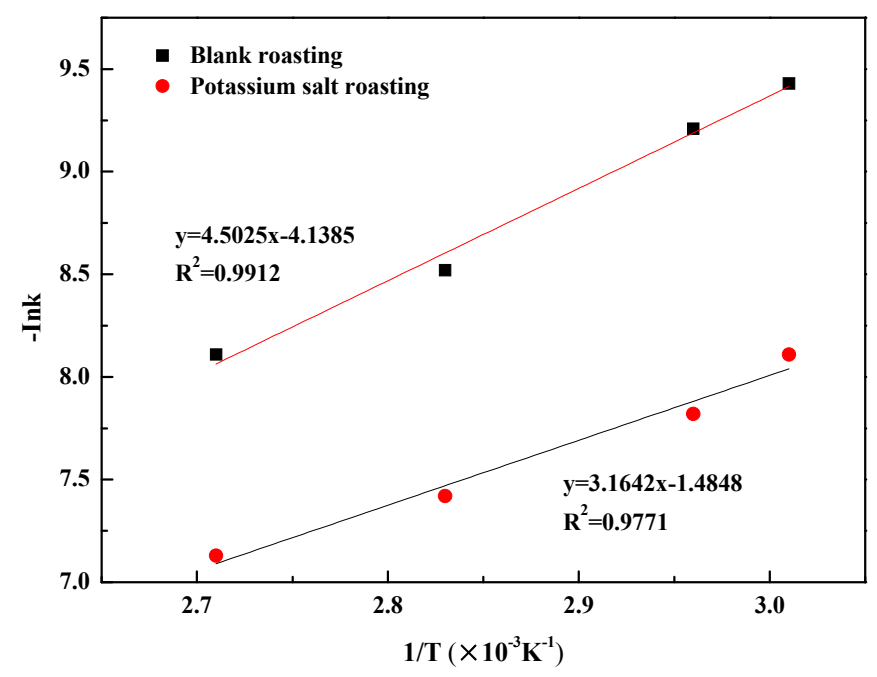

Figure 12. Fitting plots of $-\operatorname{lnk}$ and $1 / \mathrm{T}$. 


\subsubsection{Calculation of Reaction Orders}

Substituting the experimental data in Figure $6 \mathrm{~b}$ to Equation (8), the fitting results are illustrated in Figure 13.

According to the leaching rate formula, the leaching kinetics equation can be deduced:

$$
\operatorname{lnk}=\ln k_{0}-\mathrm{E} / \mathrm{RT}+\mathrm{nlnC}
$$

where $\mathrm{k}$ is the apparent reaction rate constant, $\mathrm{E}$ is the apparent activation energy $(\mathrm{kJ} / \mathrm{mol}), \mathrm{T}$ is the leaching temperature $(\mathrm{K}), \mathrm{C}$ is the sulfuric acid concentration $(v / v)$, and $\mathrm{n}$ is the reaction order.

It can be obtained from the Equation (11) that $\operatorname{lnk}$ and $\ln C$ have a linear relationship; additionally, the slope is $-\mathrm{E} / \mathrm{R}$. Thus, the reaction order can be inferred from the slope. The logarithm of the reaction rate constant $\mathrm{k}$ of the roasting slag in the acid leaching process and the logarithm of sulfuric acid concentration were plotted; the results are illustrated in Figure 14.

As shown in Figure 14, the reaction order of the blank roasting with regards to sulfuric acid concentration is 0.6588 ; similarly, with potassium salt roasting, this is 0.5799 . Moreover, when the vanadium-titanium magnetite was roasted with the potassium salt additive, the dependency on a high sulfuric acid concentration in the leaching process could be reduced.

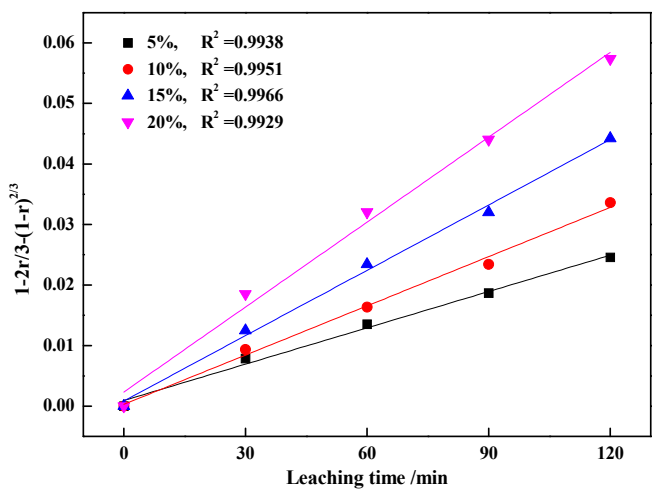

(a)

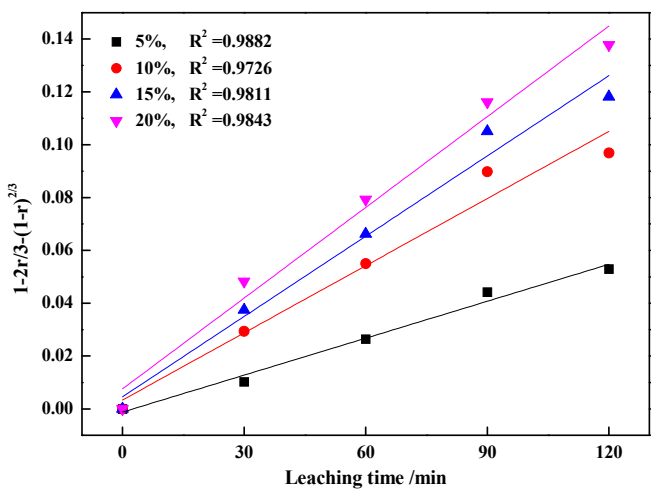

(b)

Figure 13. Fitting plots of Equation (8) versus time at different sulfuric acid concentrations. (a) blank roasting; (b) potassium salt roasting.

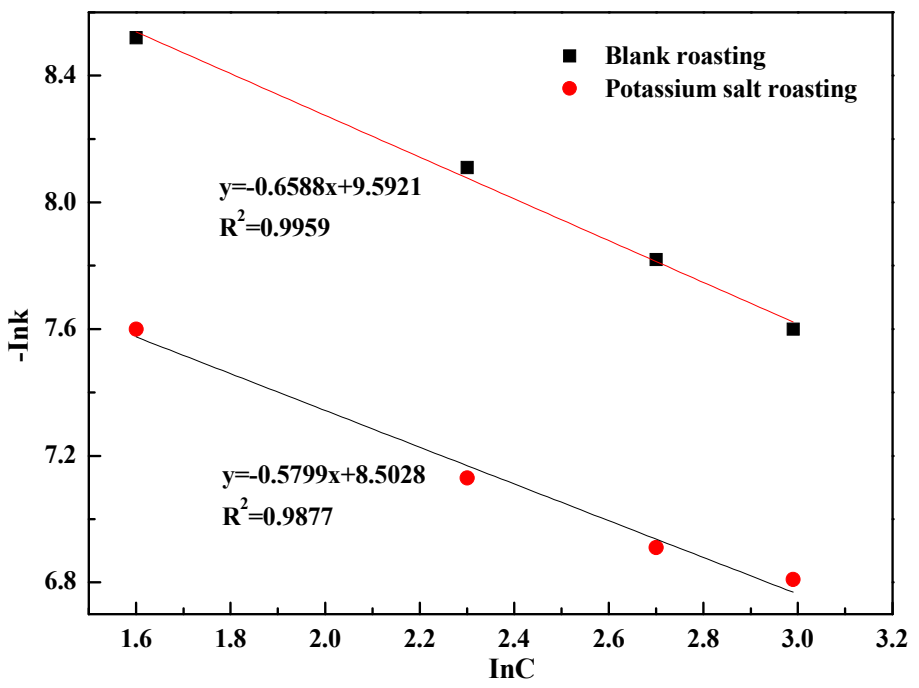

Figure 14. Fitting plots of $-\operatorname{lnk}$ and $\ln C$. 


\section{Conclusions}

1. The effects of potassium salt roasting additives were more efficient than traditional sodium and calcium salt. Particularly, $\mathrm{K}_{2} \mathrm{SO}_{4}$ was preferred as the roasting additive. Under certain conditions (the dosage of $\mathrm{K}_{2} \mathrm{SO}_{4}$ was $4 \mathrm{wt} \%$, the roasting temperature was $900{ }^{\circ} \mathrm{C}$, the roasting time was $1 \mathrm{~h}$, the leaching temperature was $95^{\circ} \mathrm{C}$, the sulfuric acid concentration was $10 \%(v / v)$, and the leaching time was $1.5 \mathrm{~h}$, with a liquid to solid ratio of $3 \mathrm{~mL} / \mathrm{g}$ ) the vanadium leaching efficiency increased from $41.17 \%$ with blank roasting to $71.37 \%$.

2. $\mathrm{K}_{2} \mathrm{SO}_{4}$ could fully destroy the structure of vanadium-bearing minerals such as magnetite, and could promote the formation of $\mathrm{KVO}_{3}$ to inhibit the formation of $\mathrm{Ca}\left(\mathrm{VO}_{3}\right)_{2}$ in the roasting process. Moreover, promoting the dissolution of sphene to release its vanadium in the leaching process significantly increases the vanadium leaching efficiency.

3. The leaching process was controlled by internal diffusion; the apparent activation energy decreased from $37.43 \mathrm{~kJ} / \mathrm{mol}$ of blank roasting to $26.31 \mathrm{~kJ} / \mathrm{mol}$ of potassium salt roasting. At the same time, the reaction order with regard to sulfuric acid concentration decreased from 0.6588 to 0.5799. Therefore, potassium salt roasting could accelerate the leaching process and reduce the dependence on high temperature and high acidity to improve mineral activity.

Acknowledgments: This research was funded by the Project in the National Science \& Technology Pillar Program of China (No. 2015BAB18B01; No. 2015BAB18B00).

Author Contributions: Renmin Li and Tao Liu conceived and designed the experiments; Renmin Li performed the experiments; Renmin Li and Chengbao Xu analyzed the data; Tao Liu, Yimin Zhang and Jing Huang contributed reagents/materials/analysis tools; Renmin Li wrote this paper.

Conflicts of Interest: The authors declare no conflict of interest.

\section{References}

1. Zhang, Y.M.; Bao, S.X.; Liu, T.; Chen, T.J.; Huang, J. The technology of extracting vanadium from stone coal in China: History, current status and future prospects. Hydrometallurgy. 2011, 109, 116-124. [CrossRef]

2. Zhu, X.B.; Li, W.; Guan, X.M. Vanadium extraction from titano-magnetite by hydrofluoric acid. Int. J. Miner. Process. 2016, 157, 55-59. [CrossRef]

3. Qiu, H.D.; Zhang, H.; Zhao, B.; Zhu, J.F.; Liu, D.R. Dynamics study on vanadium extraction technology from chloride leaching steel slag. Rare Metal. Mater. Eng. 2013, 42, 696-699. [CrossRef]

4. Xiang, J.Y.; Huang, Q.Y.; Lv, X.W.; Bai, C.G. Multistage utilization process for the gradient-recovery of V, Fe, and Ti from vanadium-bearing converter slag. J. Hazard. Mate 2017, 336, 1-7. [CrossRef] [PubMed]

5. Ning, P.G.; Lin, X.; Wang, X.Y.; Gao, H.B. High-efficient extraction of vanadium and its application in the utilization of the chromium-bearing vanadium slag. Chem. Eng. J. 2016, 301, 132-138. [CrossRef]

6. Aarabi-Karasgani, M.; Rashchi, F.; Mostoufi, N.; Vahidi, E. Leaching of vanadium from LD converter slag using sulfuric acid. Hydrometallurgy 2010, 102, 14-21. [CrossRef]

7. Li, M.; Liu, B.; Zheng, S.L.; Wang, S.N.; Du, H.; Dreisinger, D.B.; Zhang, Y. A cleaner vanadium extraction method featuring non-salt roasting and ammonium bicarbonate leaching. J. Clean. Prod. 2017, 149, $206-217$. [CrossRef]

8. Zhang, G.Q.; Zhang, T.A.; Zhang, Y.; Lv, G.Z.; Liu, Y.; Liu, Z.L. Pressure leaching of converter vanadium slag with waste titanium dioxide. Rare Met. 2016, 35, 576-580. [CrossRef]

9. Xu, C.B.; Zhang, Y.M.; Liu, T.; Huang, J. Characterization and pre-concentration of low-grade vanadium-titanium magnetite ore. Minerals 2017, 7, 137. [CrossRef]

10. Zhao, L.S.; Wang, L.N.; Qi, T.; Chen, D.S.; Zhao, H.X.; Liu, Y.H. A novel method to extract iron, titanium, vanadium, and chromium from high-chromium vanadium-bearing titanomagnetite concentrates. Hydrometallurgy 2014, 149, 106-109. [CrossRef]

11. Li, M.; Du, H.; Zheng, S.L.; Wang, S.N.; Zhang, Y.; Liu, B.; Dreisinger, D.B.; Zhang, Y. Extraction of vanadium from vanadium slag via non-salt roasting and ammonium oxalate leaching. JOM 2017, 69, 1970-1975. [CrossRef] 
12. Li, H.Y.; Wang, K.; Hua, H.W.; Yang, Z.; Zhou, W.; Xie, B. Selective leaching of vanadium in calcification-roasted vanadium slag by ammonium carbonate. Hydrometallurgy 2016, 160, 18-25. [CrossRef]

13. Shi, Q.H.; Zhang, Y.M.; Huang, J.; Liu, T.; Liu, H.; Wang, L.Y. Synergistic solvent extraction of vanadium from leaching solution of stone coal using D2EHPA and PC88A. Sep. Purif. Technol. 2017, 181, 1-7. [CrossRef]

14. Zhang, X.F.; Liu, F.G.; Xue, X.X.; Jiang, T. Effects of microwave and conventional blank roasting on oxidation behavior, microstructure and surface morphology of vanadium slag with high chromium content. J. Alloys Compd. 2016, 686, 356-365. [CrossRef]

15. Li, L.J.; Zhang, L.; Zheng, S.L.; Lou, T.P.; Zhang, Y.; Chen, D.H.; Zhang, Y. Acid leaching of calcined vanadium titano magnetite with calcium compounds for extraction of vanadium. Chin. J. Process. Eng. 2011, 11, 573-578.

16. Li, X.S.; Xie, B.; Wang, G.E.; Li, X.J. Oxidation process of low-grade vanadium slag in presence of $\mathrm{Na}_{2} \mathrm{CO}_{3}$. Trans. Nonferrous Met. Soc. 2011, 21, 1860-1867. [CrossRef]

17. Zhao, Y.; Hong, Y.L.; Yin, X.C.; Yan, Z.M.; Yan, X.M. Leaching kinetics of calcification roasted vanadium slag with high $\mathrm{CaO}$ content by sulfuric acid. Int. J. Miner. Process. 2014, 133, 105-111.

18. Ippolito, N.M.; Innocenzi, V.; De Michelis, I.; Medici, F.; Vegliò, F. Rare earth elements recovery from fluorescent lamps: A new thermal pretreatment to improve the efficiency of the hydrometallurgical process. J. Clean. Prod. 2017, 153, 287-298. [CrossRef]

19. Innocenzi, V.; Ippolito, N.M.; De Michelis, I.; Medici, F.; Vegliò, F. A hydrometallurgical process for the recovery of rare earths from fluorescent lamps: Experimental design, optimization of terbium acid leaching process and process analysis. J. Environ. Manag. 2016, 184, 552-559. [CrossRef] [PubMed]

20. Wang, Z.; Zheng, S.; Wang, S.; Qin, Y.; Du, H.; Zhang, Y. Electrochemical decomposition of vanadium slag in concentrated $\mathrm{NaOH}$ solution. Hydrometallurgy 2015, 151, 51-55. [CrossRef]

21. Zhang, J.L.; Xing, X.D.; Cao, M.M.; Jiao, K.X.; Wang, C.L.; Ren, S. Reduction kinetics of vanadium titano-magnetite carbon composite pellets adding catalysts under high temperature. J. Iron Steel Res. Int. 2013, 20, 1-7. [CrossRef]

22. Zhu, X.B.; Zhang, Y.M.; Liu, T. Experiment and mechanism study on vanadium extraction from stone coal by activation roasting. Chin. J. Rare Met. 2013, 37, 284-288.

23. Li, H.Y.; Fang, H.X.; Wang, K.; Zhou, W.; Yang, Z.; Yan, X.M.; Ge, W.S.; Li, Q.W.; Xie, B. Asynchronous extraction of vanadium and chromium from vanadium slag by stepwise sodium roasting-water leaching. Hydrometallurgy 2015, 156, 124-135. [CrossRef]

24. Beijing General Research Institute of Mining \& Metallurgy. Chemical Phase Analyses; Metallurgical Industry Press: Beijing, China, 1979.

25. Chen, F.; Zhang, Y.M.; Huang, J.; Liu, T.; Xue, N.N. Mechanism of enhancing extraction of vanadium from stone coal by roasting with $\mathrm{MgO}$. Minerals 2017, 7. [CrossRef]

26. Higher Education Press. Inorganic Chemistry; Higher Education Press: Beijing, China, 2010.

27. Wang, B.; Liu, T.; Zhang, Y.M.; Huang, J. Effect of $\mathrm{CaF}_{2} / \mathrm{CaO}$ composite additive on roasting of vanadium-bearing stone coal and acid leaching kinetics. Minerals 2017, 7, 43. [CrossRef]

28. Hu, P.C.; Zhang, Y.M.; Liu, T.; Huang, J.; Yuan, Y.Z.; Zheng, Q.S. Highly selective separation of vanadium over iron from stone coal by oxalic acid leaching. J. Ind. Eng. Chem. 2017, 45, 241-247. [CrossRef]

29. Yuan, Y.Z.; Zhang, Y.M.; Liu, T.; Chen, T.J.; Huang, J. Source separation of V and Fe by two-stage selective leaching during V extraction from stone coal. RSC Adv. 2017, 7, 18438-18446. [CrossRef]

30. Rasoulnia, P.; Mousavi, S.M. V and Ni recovery from a vanadium-rich power plant residual ash using acid producing fungi: Aspergillus Niger and Penicillium simplicissimum. RSC Adv. 2016, 6, 9139-9151. [CrossRef]

31. Zhu, X.B.; Zhang, Y.M.; Huang, J.; Liu, T.; Wang, Y. A kinetics study of multi-stage counter-current circulation acid leaching of vanadium from stone coal. Int. J. Miner. Process. 2012, 114-117, 1-6. [CrossRef]

32. Cai, Z.L.; Zhang, Y.M.; Liu, T.; Huang, J. Mechanisms of vanadium recovery from stone coal by novel $\mathrm{BaCO}_{3} / \mathrm{CaO}$ composite additive roasting and acid leaching technology. Minerals 2016, 6, 26. [CrossRef]

33. Espiari, S.; Rashchi, F.; Sadrnezhaad, S.K. Hydrometallurgical treatment of tailings with high zinc content. Hydrometallurgy 2006, 82, 54-62. [CrossRef]

(C) 2018 by the authors. Licensee MDPI, Basel, Switzerland. This article is an open access article distributed under the terms and conditions of the Creative Commons Attribution (CC BY) license (http:/ / creativecommons.org/licenses/by/4.0/). 